\title{
Breeding Strategies for Lodging Resistance in Rice
}

\author{
Girija Rani M. ${ }^{1 *}$, Satyanarayana P. V. ${ }^{1}$, Lal Ahmed M. ${ }^{2}$, Ashok Rani Y. ${ }^{2}$, Srinivasa Rao V. ${ }^{2}$ and Jhansirani P. ${ }^{2}$
}

${ }^{1}$ Andhra Pradesh Rice Research Institute and Regional Agricultural research Station, Acharya N.G. Ranaga Agricultural University, Maruteru, West Godavari, Andhra Pradesh (534 122), India

${ }^{2}$ College of Agriculture, Acharya N G Ranaga Agricultural University, Bapatla, Guntur district, Andhra Pradesh (522 101), India

\section{Corresponding Author}

Girija Rani M.

e-mail: girija_aprri@yahoo.co.in

\begin{tabular}{l} 
Article History \\
\hline \hline Article ID: AR1793a \\
Received in $15^{\text {th }}$ March, 2017 \\
Received in revised form $21^{\text {st }}$ June, 2017 \\
Accepted in final form $10^{\text {th }}$ November, 2017
\end{tabular}

\section{Abstract}

Lodging of the rice crop is the major limiting factor to rice productivity in cyclone prone areas. Lodging not only reduces the yield but also it deteriorates grain quality impedes mechanical harvesting, increases harvesting and drying costs. Lodging resistance is complex trait influenced by environment and structural properties of the stem. Factors like cultivar, fertilizers application, irrigation, plant density, pest and disease management influences lodging apart from weather parameters. Though semi dwarf gene reduced lodging to certain extent but it resulted in yield plateau and also high yielding semi dwarf rice varieties like Swarna prone to lodging because of weak culm. Breeding for lodging resistant rice varieties is important strategy to combat adverse effects of climatic changed conditions. Direct selection for lodging resistance by visual score in segregating material is herculean task as it is influenced by structural properties of the stem and weather parameters. Type of lodging decides selection of traits suitable for lodging resistance. Stem lodging is the main type of lodging limits the rice productivity in irrigated ecosystem. This review focused on understanding the problems of lodging, effects of lodging, factors influencing lodging resistance, physiological basis of lodging, breeding for lodging resistance and Quantitative trait loci (QTLs) associated with lodging resistance related traits. Root lodging prevails under direct seeded condition where root anchorage is poor. Selection suitable phenotypic traits and genotyping with suitable molecular markers would help in framing suitable breeding strategy for the development of lodging resistant rice varieties.

Keywords: Lodging resistance, rice, productivity breeding, strategy, QTLS

\section{Introduction}

Rice is the one of the major staple food crops across the world with a cultivated area of nearly 163 mha and a production of $700 \mathrm{mt}$ (FAO, 2013). India is the second largest producer of rice with diversified rice ecosystems facing major abiotic stresses caused by climatic changed condition. Lodging of rice crop is becoming major problem at reproductive phase in cyclone prone coastal irrigated rice areas. In recent climatic changed conditions, unpredicted cyclones particularly in the October and November months in Southern India causing severe damage to rice crop. This can reduce yield by up to $80 \%$ and causes several knock-on effects including reduced grain quality, greater drying costs and slower harvest (Berry et al., 2004). Breeding for lodging resistance is complex as it is influenced by structural properties of the stem and weather parameters like rainfall, wind. The stem traits contributing to lodging resistance include basal internode lengths and thickness, plant height and stem wall thickness (Chang and Vergara, 1972; Matsuda et al., 1983). Direct evaluation of lodging resistance in breeding programmes is cumbersome. Application of molecular markers is one of the strategies to develop nonlodging rice varieties (Ookawa et al., 2010) besides conventional breeding. This review focused on understanding of lodging and possible ways to develop lodging resistance varieties.

\section{The Problem of Lodging}

Lodging is the displacement of stems from their upright position. It may be permanent or partly reversible, depending upon the extent of bending. This usually occurs only after ear or panicle has emerged and results in shoots permanently leaning or lying horizontally on the ground. Heading and early grain development stages are the crucial stages of yield loss by lodging. Two types of lodging are recognized: a) stem lodging and b root lodging.

a) Stem lodging: It occurs due to bending or breakage of lower culm internodes. It occurs later in the season as the culm becomes more brittle due to crop maturation. Wind acts on 
the shoots to create a leverage force, the size of which is determined by wind speed, area of the ear and height of the crop. When this force exceeds the strength of the stem base then stem lodging occurs. The strength of the stem base is determined by the diameter, wall width and the strength of the stem wall material. Stem lodging can be classified into bending type and breaking type of lodging (Kashiwagi, 2014). First one is the bending type of lodging occurs due to bending at the middle of the internode without culm breakage. Second is the breaking type of lodging, which is characterized by breaking of internodes in the culm primarily below the third internode. The breaking type of lodging is more serious than the bending type, because bended culms are still able to transport photosynthetic assimilates from the leaves to the panicles, which is necessary for grain filling. In rice, breaking type of stem lodging is usually caused by one of the bottom internodes ( $4^{\text {th }}$ inter node) buckling and results in the upper stem and ear lying horizontally. Stem lodged plants can lean at angles of less than $90^{\circ}$ from the vertical without being supported by neighboring plants.

b) Root lodging: Leaning from the crown due to disturbance of root system results in root lodging. It is the most common type of lodging in maize and direct seeded rice. When the leverage exerted by all of the shoots belonging to a plant exceeds the strength of its anchorage system then root lodging occurs. The strength of the anchorage system is determined by the spread of the root plate and the strength of the surrounding soil. Soil strength is critical for root lodging and it is affected most by rainfall, but also by soil type and cultivations.

\section{Causes of Lodging}

Lodging in cereals is often a result of the combined effects of inadequate standing power of the crop and adverse weather conditions, such as rain, wind and hail. Lodging is also variety (cultivar) dependent. For example, a tall, weak stemmed rice cultivar has a greater tendency to lodge than a semi dwarf cultivar with stiffer straw. Under conditions of high moisture and nitrogen fertility, semi dwarf varieties are less prone to lodging than standard ones. Furthermore, short thick strawed cultivars resist lodging better than tall cultivars. Plants that are initially resistant to lodging may stand erect during favorable conditions but these plants may fall down when exceptionally bad weather, such as heavy rain or wind, prevails. A crop that lodges early will recover through the formation of "elbow joints" at the lowest stem nodes i.e., kneeing ability of the genotypes in case of bending type of lodging. The cells on the lower side of the node elongate and force the stem erect. As plants mature the stem cells mature and are no longer capable of elongation to enable plant recovery it may results in breaking type of lodging.

High nitrogen fertilization, caused plants to be more susceptible to lodging. This is due to luxurious growth which also provided an excellent environment for the spread of diseases such as sheath blight and brown plant hopper. In addition, increased plant densities, heavier seeding rates, shading and high moisture content especially under cloudy and humid conditions, have been found to increase the tendency of rice crop to lodge.

In addition the tendency of a crop to lodge depends on the resistance especially of the lower internodes. This is because the lower internodes have to resist the greatest movement of force. The weight of the higher internodes of the stems plus leaves and heads in relation to the stem (culm) will affect the resistance of a crop to lodging. The heavier the higher parts of the stem and the greater the distance from their centre of gravity to the base of the stem, the greater is the movement of the forces acting upon the lower internodes and the roots.

The tendency of a crop to lodge is dependent on its straw length. The ability of a crop to withstand lodging also depends on the length of the stems particularly the length of the peduncle (the distance from the last node to the base of the head). Some of the factors that will increase the length of the stem include: the genetic potential of the cultivar; high fertility level, especially nitrogen and low solar radiation; stem diameter and stem-wall thickness (particularly the basal internodes).

\section{Effects of Lodging}

Lodging can cause severe yield loss and poor grain quality because of reduced canopy photosynthesis, increased respiration, reduced translocation of nutrients and carbon for grain filling and increased susceptibility to pests (Hitaka, 1969). Many studies have shown that the culm characteristics contributing to lodging resistance include basal internode length and thickness, plant height, culm wall thickness, and leaf sheath wrapping and thickness (Chang and Vergara, 1972, Hojyo, 1974, Matsuda et al., 1983). Severe lodging has detrimental effects on grain formation and associated harvesting problems and losses. It takes about twice the time to harvest a lodged crop than a standing one. Secondary growth in combination with a flattened crop makes harvesting difficult and can subsequently lead to poor grain quality and high yield losses.

Yield parameters and grain quality including ratio of grain length to grain width, gelatinization temperature and gel consistency were significantly deteriorated by lodging. Lodging one day earlier to harvesting could cause $2.66 \%$ to $2.71 \%$ of yield loss, 1.8 to $2.6 \%$ decrease of filled grains, 0.26 to 0.32 g reduction of 1000 grain weight, 0.097 to $0.155 \%$ decline of milled rice rate, as well as 0.13 to $0.27 \%$ increase of chalky grain rate, and 0.021 to $0.024 \%$ rise of protein content, and subsequently lower the eating quality (Lang et al., 2012). Lodging in rice plants during ripening period results not only in reduction of grain yield, owing to decreased canopy photosynthesis as result of self shading, 
but also decrease in grain quality due to increased browning of rice (Setter et al., 1997 ).

Lodging often contributes to uneven maturity, high moisture content and loss of grain quality due to sprouting and possible moulding. Lodging have a greater impact on whole grain (head rice) milling yield than total grain milling yield as head rice yield reductions of 30.19 to $55.30 \mathrm{~g} \mathrm{~kg}^{-1}$ were observed (Salassi et al., 2013). Excessive moisture has often delayed harvest and may necessitate grain drying. Lodging can cause severe harvesting problems due to green, immature grains and slowing of the combine harvester speed. All the above can result in increased harvesting costs.

\section{Factors Influencing Lodging Resistance}

Several factors like soil condition, input management, wind speed, structural properties of the varieties influences the lodging of the crop. Continuous soil saturation significantly increased lodging resistance compared to continuous submergence (Tabbal et al., 2004). Lodging resistant genotypes exhibited wider culm diameter at $4^{\text {th }}$ internode and it was decreased with increased planting density (Mobasser et al., 2009). Increasing of nitrogen rate and transplanting density, results in increase in the plant height and length of basal internodes, the diameter of stem and the wall thickness of culm reduced leading to the lodging of the crop (Shi-Min et al., 2009). Application of potash significantly increased stem diameter (30-80\%) in dwarf varieties with reduced lodging tendency (Bhiah et al., 2010). Sheath blight intensity was negatively related with breaking resistance and positively related with lodging index. Sheath blight reduced the breaking resistance of lower internodes and consequently resulted in poor lodging resistance (Wu et al., 2012). Maximum lodging resistance expressed in terms of maximum breaking resistance and maximum $4^{\text {th }}$ internodal length, $3^{\text {rd }}$ and $4^{\text {th }}$ internode bending moment, $3^{\text {rd }}$ and $4^{\text {th }}$ internodes lodging index and straw yield in conventional method of cultivation (Salman et al., 2013).

\section{Physiological Basis of Lodging}

Plant height is an important factor in terms of lodging susceptibility, but lodging susceptibility also depends on other traits. Panicle weight to height ratio is a useful parameter. The plant's center of gravity is an important parameter to consider for lodging susceptibility. Stem breaking strength is the result of reinforcement by leaf sheaths and culm strength (culm thickness and culm stiffness). Leaf star is a recently developed lodging resistant variety at Japan with a thick culm, well developed thick cortical fiber tissue, with high lignin and high cellulose densities. Re-accumulation of stem Non Structural Carbohydrates (NSC) in the later period of grain filling related to slower senescence and is correlated with lodging resistance. The stage with least stem NSC is most prone to lodging. Biomass production before heading has an effect on lodging resistance. Silicon has been observed to play a role in structural properties, and is important for some sucrose biosynthesis enzymes.

In some cases the plants may become more vertical after lodging. This recovery is more likely when full lodging does not occur. There is a distinction between elasticity and repair in terms of lodging recovery. It is uncertain if rice is able to re-orient the stem by gravitropic response after lodging, or if recovery is simply from drying of the stem and panicle which reduces the weight that forced the stem to lodge initially. Node bending is observed during lodging recovery, and there are large differences in node bending. Rice has a kneeing ability but not all the genotypes. Re-accumulation of stem carbohydrates after grain filling has been observed in several rice genotypes and may play a role in lodging recovery. There are likely metabolic costs of component traits for lodging resistance. However there is potential for stem strength that does not necessarily incur a metabolic cost (e.g. less total lignin but more concentrated in a thin layer). These alternate configurations of lignifications for stem strength have been observed in rice and sorghum.

Density of lignin is the main factor responsible for the varietal difference in the bending stress related to lodging resistance of rice (Ookawa and Ishihara, 1993). Lignin and cellulose determine physical strength, as lower lignin or cellulose contents cause the culm to be brittle ( $\mathrm{Ma}$ et al., 2002). In the rice mutant brittle culm1 (bc1), altered biosynthesis of cellulose, hemicelluloses and lignin in culms reduced secondary cell wall thickness and mechanical strength. Greater accumulation of starch increases the bending strength and stiffness of the culm (Kashiwagi et al., 2006). Higher silicon contents are also related to physical strength (Ma and Yamaji, 2006). Locus for pushing resistance in the lowest part of rice plant (pr15) increased the weight of lowest stem and thus increases the lodging resistance (Kashiwagi and Ishimaru, 2004).

Lower nitrogen and higher potassium contents in internode help to decrease the lodging tendency of a variety (Mahbub et al., 2006). Lower bending moment, higher culm strength and tightly wrapping of the leaf sheath make a variety tolerant to lodging. The physical strength was positively and highly significantly correlated with the total amount of $K$ and $\mathrm{Si}$ in culm during grain filling, and highly significantly with the total amount of soluble sugars in culm at the full heading and milky stages (Zhang et al., 2009). Resistance of rice basal stems was very significantly positive correlated to $\mathrm{SiO} 2$ and soluble sugar contents in rice stem of the reproductive stage $(p<0.01)$, which had a certain relationship with lodging resistance of rice (Yan-Hua et al., 2011). Silicon had positive effects on plant height, internode length, fresh weight, breaking resistance, bending moment, culm thickness, roots, stems, green leaves and total dry weight. A sufficient supply of Si has an effect on the stability of culms and serves to decrease the risk of lodging for rice plants (Fallah, 2012). 
Application of growth regulator paclobutrazol either 50 or 100 ppm gave significant retardation of internodes and gave higher stem bending resistance with significant increase in yield (Sinniah et al., 2012). Higher $\left[\mathrm{CO}_{2}\right]$ can enhance the risk of stem lodging for cultivars with strong $\left[\mathrm{CO}_{2}\right]$ responses, but may not aggravate the root lodging for all rice cultivars (Zhu et al., 2013). Plants with lower Gibberellic acid improved bending type lodging resistance due to their short stature but reduced breaking type of lodging resistance and total biomass. Plants producing high amounts of $\mathrm{GA}$, the bending type lodging resistance were minimum. The breaking type lodging resistance was improved due to increased lignin accumulation or larger culm diameters (Okuno et al., 2014).

\section{Breeding for Lodging Resistance}

Traditional breeding for high yielding rice has been dependent on the widespread use of fertilizers and the cultivation of gibberellin (GA) deficient semi dwarf varieties. Efforts for breeding for lodging resistance mainly focused on development of semi dwarf varieties. High yielding semi dwarf varieties more often prone to lodging because of their weak culms under adverse climate conditions. Although green revolution has been successful in increasing grain yield, it is desirable to further improve grain production and also to breed for high biomass.

The sd1 (dee-geo-woo-gen dwarf) gene has contributed to develop short culm and high yielding varieties in Southeast Asia and other areas. The genes responsible for imparting short stature to rice used in the Green Revolution have been identified by Sasaki et al., 2002 in the synthesis or signaling of gibberellin (GA). Only a single gene, semi dwarfm1 ( $s d$ $1)$, is used widely for producing semi dwarf rice, although there are many alleles of this gene. The wild type enzyme OsGA200x2 is a GA 20 oxidase, which catalyzes three steps in the biosynthetic pathway. Rice plants lacking this enzyme are slightly reduced in height and there are no detrimental effects on grain yields. The rice dwarfing gene arose as a spontaneous mutation in the Taiwanese indica strain woo-gen. The $s d-1$ allele in dee-geo-woo-gen contains a 383-base-pair deletion, which introduces a stop codon so that a truncated, inactive enzyme GA 20 Oxidase would be produced.

Molecular characterization of small organ size1 (smos1) mutant revealed that it contains a mutation in a gene coding for APETALA2 (AP2)-type transcription factor which acts as an auxin dependent regulator of cell expansion. Thus, the mutation results in decreased ability of the cells to expand. The mutant also exhibits an increase in cell numbers in several organs which could account for smos1's high lodging resistance (Hirano et al., 2014).

Direct evaluation of lodging resistance requires visual estimates in plots of advanced breeding lines or cultivars. A true assessment needs simulating conditions favorable to lodging, with a large investment of time, money and resources. But even routine plot scoring cannot be used to evaluate first generations in breeding programs, because their genetic variability is too high to grow plots. An alternative way for improving lodging resistance is the use of indirect selection criteria. Although the traditional target has been a reduction of height, pushing resistance has also been used in individual plants of maize and rice (Terashima et al., 1992), particularly lower parts of the rice plant (Kashiwagi and Ishimaru, 2004). The more stems with tightly wrapped sheaths the more strength of lodging resistant stems in rice, as well the more thick sheath wrapped, the stronger the ability of lodging resistant stems (Wang et al., 1998, Rao et al., 2009).

\section{Lodging Related Traits}

The following characters more useful selection criteria in breeding for lodging resistance genotypes.

a) Culm Diameter $(\mathrm{mm})$ : Stem lodging occurs due to breakage at lower internodes. Culm diameter was measured at $4^{\text {th }}$ inter node from the top at 20 days after heading using vernier calipers and expressed in millimeters ( $\mathrm{mm}$ ).

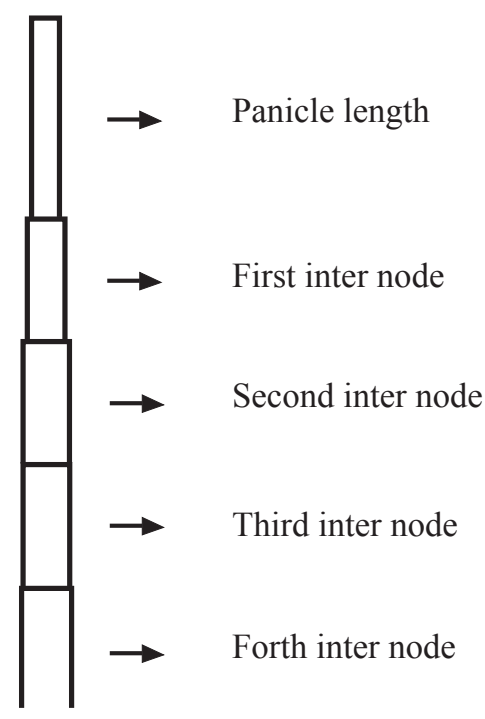

b) Culm thickness $(\mathrm{mm})$ : The culm internodes were cut transversely at $4^{\text {th }}$ inter node from the top at 20 days after heading with a scalpel to measure the inner and outer diameters of the inter node with a vernier calipers. The averaged culm wall thickness was then calculated by the following equation

Culm wall thickness=(outer diameter - inner diameter $) / 2$.

c) $4^{\text {th }}$ Inter nodal length $(\mathrm{cm})$ : Inter nodal length from between 4 and 5 nodes from the top was measured and expressed in $\mathrm{cm}$.

d) Culm strength: Culm strength at the maturity stage was rated based on the inclination of the tillers as per the SES of IRRI, 2002 by pushing hill forward and back for few times at 
maturity.

Scale (plants lodged)

1 Strong (no bending)

3 Moderately strong (most plants bending)

5 Intermediate (Most plants moderately bending)

7 Weak (most plants nearly flat)

9 very weak (all plants are flat)

e) Bending Strength (g stem ${ }^{-1}$ ): It was measured by pushing hill at $20 \mathrm{~cm}$ above the ground at $45^{\circ}$ angle using Prostrate tester (DIK 7401, Daiki Rika Kogyo Co. Lt d., Tokyo, Japan and it was expressed in $\mathrm{g} / \mathrm{stem}$ using the following formula as per Bhagat et al., 2011.

Bending strength $=[$ (test reading $/ 40) \times(1000 /$ no. of tillers $)]$

f) Per cent of Lodging: Lodging incidence was determined as per cent ratio of plants lodged as per IRRI, 2002 standard evaluation system (SES) under natural conditions at maturity stage.

\section{Conventional Plant Breeding Approaches}

Several researchers studied lodging resistance related traits for establishing breeding programmes. Negative correlation between internode length and lodging resistance and a positive correlation of culm diameter with lodging resistance in $\mathrm{M}_{2}$ generation of tall PMK1 and and Poonagar upland varieties was observed (Arumugampillai and Subramanian, 1990). Lodging resistance related traits like culm thickness, culm strength, basal internodal length and per cent of lodging expressed duplicate type of epistasis (Girija Rani et al., 2015). Susceptibility of lodging differs in cultivars with similar plant height. Stem diameter and weight is positively correlated with lodging resistance and breaking strength of the stem (Ookawa and Ishihara, 1992). Breaking strength of the stem was doubled due to leaf sheath wrapping and tripled due to larger cross sectional area of the stem. Positive correlation between pushing resistance and lodging in paddy field crops was observed (Terashima et al., 1992). Thicker culms were associated with larger panicles and breaking resistant strength of culm was positively correlated with the amount of dry matter stored in stem and thickness of culm. Lodging index was positively correlated with plant height and bending moment, negatively correlated with thickness of culm and breaking resistant strength (Hui-jie et al., 2000).

Culm diameter, culm wall thickness, the number of big and small vascular bundles correlated with lodging resistance and selection of rigid stem will improve lodging resistance (Chuanren et al., 2004, Li et al., 2011). Manipulations in culm length from the ground to the ear and weight of the lower stem would improve sturdiness of the lower part, thus increasing lodging resistance, without affecting yield ( Kashiwagi et al., 2005). Dry weight per unit length, breaking resistance and lodging index of lower nodes were significantly correlated with visual score of lodging (Islam et al., 2007, Laza et al., 2014). Ideal physical characteristics of lodging resistance are short basal and secondary nodes, longer major and minor axis of cross section of basal stem, wider wall thickness and bigger area of wall section of basal stem (Zhong et al., 2007).

Rigidity of upper culm with higher starch content is responsible for higher lodging resistance as a result of delayed senescence in near isogenic lines of Koshikari with lodging resistance (Ishimaru et al., 2008). Leaf sheath can delay the aging of stem and increase the strength of the stem, as well as increase plant lodging resistance by enhancing the mechanical strength of stem and sheath in rice (Kashiwagi et al., 2008). High heritability along with high genetic gain was observed for lodging percentage among 80 rice genotypes (Pal et al., 2010).

Parental lines and hybrid combinations with culm characteristics of middle plant height, roundish stem, shorter basal internode and longer top 1st internode should be selected to improve lodging resistance in super-high-yield hybrid rice breeding (Zhi-yong and Guo-hui, 2010). Two indirect methods for evaluation of lodging resistance in field conditions: the recovery ability after bending (measured as the tiller angle difference before and after bending); and, to test the sturdiness of the lower part of the plant measured as resistance to pulling could be useful in selection of lodging resistant breeding lines (Torro et al., 2011).

Large culm cultivars exhibited greater plant size, culm diameter and flag leaf length and width, as well as lower tiller numbers. The large culm cultivars also exhibited larger leaf vascular bundles, more culm vascular bundles, more grains per panicle and blighted grains, lower seed setting rates, and larger panicles. The transpiration rate was significantly higher in the large culm cultivars, whereas instantaneous water use efficiency was lower compared to the common cultivars (Wu et al., 2011).

Pedigree analysis showed lodging resistance of varieties was closely correlated with that of their parents. Among the parental traits, plant height, internode lengths, thickness of internode wall and diameter of node have significant correlation with lodging resistance. Lodging resistant parents help improve lodging resistance of bred varieties (Mingliang et al., 2012). Breaking resistance strengths of three elongation internodes near stem base were significantly correlated with internode wall thickness. Lodging index of each internode was significantly negatively correlated with corresponding internode wall thickness. As panicle length was significantly positively correlated with internode wall thickness, increasing base elongation internode wall thickness was beneficial to longer panicle breeds (Yang et al., 2012).

\section{QTLs Associated with Lodging Resistance Related Traits}

Analysis of Quantitative Trait Loci (QTLs) can reveal genetic basis of relationships among traits and allow comprehensive 
investigation of the genetic relationships among the morphological and physiological traits (Ishimaru et al., 2001). Six additive QTLs and eight pairs of epistatic QTLs associated with culm traits viz., basal culm thickness, culm length and culm strength of doubled haploid population, derived from a cross between japonica upland rice IRAT109 and japonica paddy rice Yuefu will be useful in selection of lodging resistant lines (Mu et al., 2004).

One QTL from Kasalath on chromosome 5 (pr/5) had a positive effect for pushing resistance (Kashiwagi and Ishimaru, 2004), seven QTLs controlling the number of large vascular bundies in peduncle on chromosome 1,2,3,4,7 and 10 in advanced backcross population $\left(\mathrm{BC}_{3} \mathrm{~F}_{2}\right)$, derived from the cross between Yuanjiang common and Teqing (Yan-Hui et al., 2005). QTLs related to lodging resistance and plant height on chromosome 8 by using the double haploid population from the cross of Zhaiyeqing 8 and Jingxi 1 were detected (Hu et al., 2008).

Seventeen QTL regions associated with one or more basal internodal traits and nine QTLs affecting two lower elongated internodes were expected to contribute to lodging resistance of rice were identified (Zhu et al., 2008). Ghd7 is a key transcriptional factor in the rice flowering pathway. It has significant effects on grain number, which increases grain yield (Xue et al., 2008). The NILs that carry the functional allele of Ghd7 have much better developed vascular systems, which increase transport capacity and enhance plant mechanical strength against lodging.

Effective quantitative trait loci (QTL) for culm diameter, STRONG CULM2 (SCM2) on chromosome 6 with flanking markers RM20546-RM20562 and cloned QTL conferred lodging resistance in the near isogenic lines developed in cross between Habataki and the japonica variety Sasanishiki. Presence of SCM2 in near isogenic lines showed enhanced culm strength and spikelet number as cloned SCM2 gene identical to Apparent Panicle Organisation1 (APO1). Wider culm diameter with thinner wall maximized lodging resistance without reducing yield potential (Ookawa et al., 2010). SCM2 was the rice gene regulating vascular development and first branch of panicle to affect the yield and rice harvest index and to enhance plant lodging resistance (Terao et al., 2010). QTL identified for leaf sheath length identified using double haploid (DH) population derived from a typical cross between an indica rice TN1 and a japonica rice CJ06 on chromosome 6 between RM 3 and RM 162 is in vicinity of SCM2 (Liu et al., 2011)

QTLs were detected for lodging resistance, stem and root mechanical and morphological traits, number of tillers, plant height and days to heading by using $102 \mathrm{~F}_{5}$ RILs derived from the cross between tropical japonica IR 69093-41-2-3-2, a new plant type (NPT), and indica variety, IR72 ( Barlaan et al., 2013). QTLs for strong culm on chromosome 1, 5, 6, 8 and 11 using chromosomal substitution lines were detected
(Yamamoto et al., 2013). Additional functional analysis of QTL on chromosome 11 indicated that the thick cortical fiber and high densities of cell wall components increased bending stress.

A QTL for breaking strength of the top three internodes on chromosome 11 was detected and this confers resistance to bending type of lodging in typhoon affected areas (Kashiwagi, 2014). An effective quantitative trait loci (QTL), STRONG CULM3 (SCM3), confers culm strength and the causal gene of which is identical to rice TEOSINTE BRANCHED1 (OSTB1), a gene previously reported to positively control strigolactone (SL) signaling. A near-isogenic line (NIL) carrying SCM3 showed enhanced culm strength and increased spikelet number despite the expected decrease in tiller number, indicating that $\mathrm{SL}$ also has a positive role in enhancing culm strength and spikelet number. The NIL-SCM2+SCM3 showed a much stronger culm than NIL-SCM2 and NIL-SCM3 and an increased spikelet number caused by the additive effect of these QTLs (Yano et al., 2014).

Gold hull and internode2 (gh2) identified as lignin deficient has been mapped to the short arm of chromosome 2 and it encodes cinnamyl-alcohol dehydrogenase (Ookawa et al., 2014). Rice can be improved for forage and bioenergy production by combining superior lodging resistance, which can be obtained by introducing thick and stiff culm traits, with low lignin concentrations.

\section{Conclusion}

In rice, considerable loss in yield and quality occurs due to lodging at reproductive phase. So far breeders have countered lodging risk by developing dwarf plants. Despite short stature, rice varieties prone to lodging under intensive agricultural management practices. Therefore, breeders must exploit wide genetic variation for strong culm traits for the development of nonlodging varieties. Precise selection of lodging resistant genotypes in early generations using suitable molecular markers can be adopted to foster future breeding programmes for climatic resilience.

\section{References}

Arumugampillai, M., Subramanian, M., 1990. Induced lodging resistance in upland rice. Mutation Breeding Newsletter, 36.

Barlaan, E.A., Sato, H., Hirabayashi, H., Ikeda, R., Imbe, T., 2013. Quantitative trait loci analysis of lodging resistance in a rice recombinant inbred line population in irrigated lowlands. In: Proceedings of $7^{\text {th }}$ International Rice Symposium, 5-8 November 2013, International Rice Research Institute, Philippines, 193.

Berry, P.M., Sterling, M., Spink, J.H., Baker, C.J., SylvesterBradley, R., Mooney, S.J., Tams, A.R., Ennos, A.R., 2004. Understanding and reducing lodging in cereals. Advances in Agronomy 84, 217-271. 
Bhagat, K.P., Sairam, R.K., Deshmukh, P.S., Kushwaha, S.R., 2011. Biochemical analysis of stem in lodging tolerant and susceptible wheat (Triticum aestivum L.) genotypes under normal and late sown conditions. Indian Journal of Plant Physiology 16(1), 68-74.

Bhiah, K.M., Guppy, C., Lockwood, P., Jessop, R., 2010. Effect of potassium on rice lodging under high nitrogen nutrition. In: Proceedings of $19^{\text {th }}$ World Congress of Soil Science, Soil Solutions for a Changing World, $1-6$ August 2010, Brisbane, Australia, 136-138.

Chang, T.T., Vergara, B.S., 1972. Ecological and genetic information on adaptability and yielding ability in tropical varieties. In: International Rice Research Institute (Eds.), Rice Breeding. International Rice Research Institute, Manila, Philippines, 431.

Chuanren, D., Bochu, W., Pingqing, W., Daohong, W., Shaoxi, C., 2004. Relationship between the minute structure and the lodging resistance of rice stems. Colloids and Surfaces B: Biointerfaces 3, 155-158.

Fallah, A., 2012. Silicon effect on lodging parameters of rice plants under hydroponic culture. International Journal of Agricultural Science 2(7), 630-634.

FAO, 2013. http://faostat.fao.org

Girija Rani, M., Satyanaryna, P.V., Lalahmed, M., Ashoka Rani, Y., Srinivasarai, V., 2015. Gene action of elite rice lines for yield and lodging resistance related traits in rice. Research on crops 16(4), 689-697.

Hirano, K., Okuno, A., Hobo, T., Ordonio, R., Shinozaki, Y., Asano, K., Kitano, H., Matsuok, M., 2014. Utilization of stiff culm trait of Rice smos1 mutant for increased lodging resistance. PLOS ONE 9(7), e96009.

Hitaka, H., 1969. Studies on the lodging of rice plants. Journal of Agricultural Research 4(3), 1-6.

Hojyo, Y., 1974. Lodging and stiffness of culms in crops. Agricultural Technology 29, 157-162.

Hu, J., Fujimoto, K., Guo, L.B., Zeng, D.L., Zhang, G.H., Dong, G.J., Wang, X.H., Zhu, L.H., Qian, Q., 2008. QTL analysis of lodging resistance force and lodging resistance related traits in rice. Chinese Journal of Rice Science 22(2), 211-214.

Hui-jie, Y., Ren-cui, Y., Yi-zhen, L., Zhao-wei, J., Sheng, J., 2000. Relationship between culm traits and lodging resistance of rice cultivars. Fujian Journal of Agricultural Sciences, 2.

Ishimaru, K., Togawa, E., Ookawa, T., Kahsiwagi, T., Madoka, Y., Hirots, N., 2008. New target for rice lodging resistance and its effect in typhoon. Planta 227 (3), 601-609.

Ishimaru, K., Yano, M., Aoki, N., Ono, K., Hirose, T., Lin, S.Y., Monica, L., Sasaki, T., Ohsugi, R., 2001. Towards the mapping of physiological and agronomic characters on a rice function map: QTL analysis and comparison between QTLs and expressed sequence tags. Theoretical Applied Genetics 102, 793-800.
Islam, M.S., Peng, S., Visperas, R.M., Ereful, N., Bhuiya, M.S.U., Julwquar, A.W., 2007. Lodging related morphological traits of hybrid rice in a tropical irrigated ecosystem. Field Crops Research 101, 240-248.

Kashiwagi T., Togawa E., Hirotsu, N., Ishimaru, K., 2008. Improvement of lodging resistance with QTLs for stem diameter in rice (Oryza sativa L.). Theoretical Applied Genetics 117, 749-757.

Kashiwagi, T., Ishimaru, K., 2004. Identification, functional analysis of a locus for improvement of lodging resistance in rice. Plant Physiology 134, 676-683.

Kashiwagi, T., Madoka, Y., Hirotsu, N., Ishimaru, K., 2006. Locus prl5 improves lodging resistance of rice by delaying senescence and increasing carbohydrate reaccumulation. Plant Physiology Biochemistry 44, 152157.

Kashiwagi, T., Sasaki, H., Ishimaru, K., 2005. Factors responsible for decreasing sturdiness of the lower part in lodging of rice (Oryza sativa L.). Plant Production Science 2, 166-172.

Kashiwagi. T., 2014. Identification of quantitative trait loci for resistance to bending-type lodging in rice (Oryza sativa L.). Euphytica. 198(3), 353-367.

Lang, Y.Z., Yang, X.D., Wang, M., Zhu, Q., 2012. Effects of lodging at different filling stages on rice yield and grain quality. Rice Science 19 (4), 315-319.

Laza, M.R., Shrestha, S., Mendez, K.V., Dingkuhn, M., Lopez, M., 2014. Morphological characterization of component traits for lodging resistance in rice. In: Abstracts of International Rice Congress 2014, October 27 to November 1, 2014, Bangkok, 1354.

Li, X., Mao, T., Fu, L., Wang,Y., Sui, X., Ren, H., Li, B., 2011. Studies on lodging resistance of rice culms and influencing factors in different harvest periods in coastal areas. Chinese Agricultural Science Bulletin, 7.

Liu, H., Rao, Y., Yang, Y., Leng, Y., Huang, L., Zhang, G., Hu, J., Guo, L., Gao , Z., Zhu, L., Dong, G., Liu, J., Yan, M., Qian, Q., Zeng, D., 2011. Genetic analysis of traits related to leaf sheath in rice (Oryza Sativa L.). Rice Genomics and Genetics 2 (3), 21-30.

Ma, J.F., Yamaji, N., 2006. Silicon uptake and accumulation in higher plants. Trends in Plant Science 11, 392-397.

Ma, Q.H., Xu, Y., Lin, Z.B., He, P., 2002. Cloning of cDNA encoding COTM from wheat which is differentially expressed in lodging sensitive and resistant cultivars. Journal of Experimental Botany 53, 2281-2282.

Mahbub, M.A.A., Khanam, M., Rahman, M.S., Hossain, M.A., Gomosta, A.R., 2006. Determination of lodging characters of some BRRI, recommended rice varieties at three nitrogen levels during wet season in Bangladesh. Bangladesh Journal of Botany 35(2), 117-124.

Matsuda, T., Kawahara, H., Chonan, N., 1983. Histological studies on breaking resistance of lower internodes in rice culm IV. The rules of each tissue of internode and 
leaf sheath in breaking resistance. Proceedings of Crop Science Society of Japan 52, 355-361.

Ming-liang, D., Zhen-xi, A., Qian, Z., Zhen-hua, Yu-min., C., Wei-hua., L., Lu-yuan, D., 2012. Relationship between lodging resistance and either agronomic traits or parents lodging resistance in plateau japonica rice. Chinese Journal of Rice Science 26(3), 325-330.

Mobasser, H.R., Yadi, R., Azizi, M., Ghanbari, A.M., Samdaliri, M., 2009. Effect of density on morphological characteristics related-lodging on yield and yield components in varieties rice (Oryza sativa L.) in Iran. American-Eurasian Journal of Agriculture \& Environmental Sciences 5(6), 745-754.

Mu, P., Zi-chao, L., Chun-ping, L., Hong-liang, Z., Xiangkun, W., 2004. QTL analysis for lodging resistance in rice using a $\mathrm{DH}$ Population under lowland and upland cultural Conditions. Proceedings of the $4^{\text {th }}$ International Crop Science Congress $26^{\text {th }}$ September- $1^{\text {st }}$ October 2004, Brisbane, Australia.

Okuno, A., Hirano, K., Asano, K., Takase, W., Masuda, R., Morinaka, Y., Ueguchitanaka, M., Kitano, H., 2014. New approach to increasing rice lodging resistance and biomass yield through the use of high gibberellin producing varieties. PLOS ONE 9(2), e86870.

Ookawa, T., Ishihara, K., 1993. Varietal difference of the cell wall components affecting the bending stress of the culm in relation to the lodging resistance in paddy rice. Japanese Journal of Crop Science 62(3), 378-384.

Ookawa, T., Ishihara, K., 1992. Varietal difference of physical characteristics of the culm related to lodging resistance in paddy. Japanese Journal of Crop Science 61(3), 419425.

Ookawa, T., Inoue, K., Matsuoka, M., Ebitani, T., Takarada, T., Yamamoto, T., Ueda, T., Yokoyama, T., Sugiyama, Nakaba, S., F, Funada, R., Kato, H, Kanekatsu, M., Toyota, K., Motobayashi, T., Vazirzanjani, M., Tojo, S., Hirasawa, T., 2014. Increased lodging resistance in long-culm, low-lignin gh2 rice for improved feed and bioenergy production. Chinese Journal Scientific Reports 4, 6567.

Ookawa, T., Hobo, T., Yano, M., Murate, K., Ando, T., Miure, H., Asno, K., Ochiai, Y., Ikeda, M., Nishitani, R., Ebistani, T., Ozaki, I., Angeles, E.R., Hirasana, T., Matsuoka, M., 2010. New approach for rice improvement using a pleiotropic QTL gene for lodging resistance and yield. Nature Communications, doi: 10.1038/ncomms1132.

Pal, A.K., Sabesan, T., 2010. Studies on genetic variability for lodging related traits in rice (Oryza sativa L.) Electronic Journal of Plant Breeding 1(3), 301-304.

Rao, Y.C., Li, Y., Dong, G.J., Zeng, D.L., Qian, Q., 2009. Progress of research on lodging resistance in rice, Zhongguo Daomi. China Rice 6, 15-19.

Salassi, M.E., Deliberto, M.A., Linscombe, S.D., Wilson, C.E., Walker, T.W., McCauley, G.N., Blouin, D.C., 2013.
Impact of harvest lodging on rough rice milling yield and market price. Agronomy Journal, 1860-1867.

Salman, D., Ghorban, N., Hamid, M., Hamid, R.M., Morteza, S.D., 2013. Evaluation of related to lodging characteristics and grain yield in Iranian rice genotypes under modified agronomical systems. Annals of Biological Research 4(2), 267-275.

Sasaki, A., Ashikari, M., Ueguchitanaka, M., Itoh, H., Nishimura, A., 2002. Green revolution: a mutant gibberellin-synthesis gene in rice. Nature 416, 701702.

SES, IRRI., 2002. Standard Evaluation System for Rice. International Rice Research Institute, Philippines.

Setter, T.L., Laureles, E.V., Mazaredo, A.M., 1997. Lodging reduces yield of rice by self-shading and reductions in canopy photosynthesis. Field Crops Research 49, 95106.

Shi-Min, Y., Li, X., Shun-Lin, Z., Jing, L., Ji-Chao, Y., 2009. Effects of nitrogen rate and transplanting density on physical andchemical characteristics and lodging resistance of culms in hybrid rice. Acta Agronomica Sinica 35 (1), 93-103.

Sinniah, U.R., Wahyuni, S., Syahputra, B.S.A., Gantait, S., 2012. A potential retardant for lodging resistance in direct seeded rice (Oryza sativa L.). Canadian Journal of Plant Science 92 (1), 13-18.

Tabbal, D., Bouman, B., Bhuiyan, S., Sibayan, E., 2004. Improving lodging resistance of direct wet-seeded rice. Philippine Journal of Crop Science 27(2), 53-62.

Terao, T., Nagata, K., Morino, K., Hirose, T., 2010. A gene controlling the number of primary rachis branches also controls the vascular bundle formation and hence is responsible to increase the harvest index and grain yield in rice. Theoretical and Applied Genetics 120(5), 875-893.

Terashima, K., Akita, S., Sakai, N., 1992. Eco-physiological characteristics related with lodging tolerance of rice in direct sowing cultivation. Japanese Journal of Crop Science 61, 380-387.

Torro, I., Breto, P., Garcia-Yzaguirre, A., 2011. Short communication-Assessing lodging resistance in rice: $A$ comparison of two indirect testing methods. Spanish Journal of Agricultural Research 9(4), 1245-1248.

Wang, Y., Li Q.Q., Li, C.H., Li, A.F., 1998. Studies on the culm quality and anatomy of wheat varieties, Zuowu Xuebao. Acta Agronomica Sinica 24(4), 452-458.

Wu, L.L., Liu, Z., Jun-Min, W., Cong-Yi, Z., Kun-Ming, C., 2011. Morphological, anatomical, and physiological characteristics involved in development of the large culm trait in rice. Australian Journal of Crop Science 5(11), 1356-1363.

Wu, W., Huang, J., Cui, K., Nie, L., Wang, Q., Yang, F., Shah, F., 2012. Sheath blight reduces stem breaking resistance and increases lodging susceptibility of rice 
plants. Field Crops Research 128, 101-108.

Xue, W.Y., Xing, Y.Z., Weng, X.Y., Zhao, Y., Tang, W.J., Wang, L., Zhou, H.J., Yu, S.B., Xu, C.G., Li, X.H., Zhang, Q.F., 2008. Natural variation in $G h d 7$ is an important regulator of heading date and yield potential in rice. Natural Genetics 40, 761-767.

Yano, K., Ookawa, T., Taiichiro, A., Aya, K., Ochiai, Y., Hirasawa, T., Ebitani, T., Takarada, T., Yano, M.,Yamamoto, T., Fukuoka, S., Wu, J., Ando, T., Ordonio, R.L., Hirano, K., Matsuoka, M., 2014. Isolation of a novel lodging resistance QTL gene involved in strigolactone signaling and its pyramiding with a QTL gene involved in another mechanism. Molecular Plant 8(2), 303-315.

Yamamoto, K., Yamamoto, T., Sugiyama, C., Hirasawa, T., Ookawa, T., 2013. Estimation of the locus for strong culm traits, using reciprocal chromosome segment substitution lines derived from the cross between rice varieties, koshihikari and takanari. In: Proceedings of $7^{\text {th }}$ International Rice Genetics Symposium $5-8^{\text {th }}$ November, 2013, Manila, Philippines, 435.

Yang, H., Fang, X., He, H., Xie, Z., 2012. Relationship of characteristics of culm construction to lodging resistance and yield of Fujian-bred super-rice cultivars. Chinese Journal of Eco Agriculture 20, 909-913.

Yan-Hua, Y., Zhen, Z., Ya-Dong, Z., Tao, C., Qing-Yong, Z., LiHui., Cai-Lin, W., 2011. Changes of stem biochemical components in different growth stages of rice and their relationship with lodging resistance. Plant Physiology Journal 47(12), 1181-1187.

Yan-Hui, J., Chuan-Qing, S., Lu-Bin, T., Yong-Cai, F., Pei-Jiang, Z., Zheng-Jin, X., Wen-Fu, C., Xiang-Kun, W., 2005. Mapping QTLs controlling vascular bundle and paniclerelated traits from Yuanjiang common Wild Rice (Oryza rufipogon Griff.). Journal of Genetics and Genomics 32(2), 178-182.

Zhang, X., Li, H., Li, W, Xu, Z, Chen, W., Zhang, W., Wang, W., 2009. The lodging resistance of erect panicle japonica rice in Northern China. Scientia Agricultura Sinica 42(7), 2305-2313.

Zhi-yong, A., Guo-hui, M., 2010. The relationship between the structure and the property of rice stem. Hybrid Rice, 6 .

Zhong, Z., Sui, G., Hua, Z., Li, Q., Hao, X., Zhu, B., Yao, J., Su, $Y ., 2007$. Analysis of lodging resistance of Tiyou 418 and Liaoyou 5218 with higher stems and bigger panicles. Chinese Agricultural Science Bulletin 23(8), 141.

Zhu, C.W., Cheng, W.G., Sakai, H., Oikawa, S., Laza, R., Usui, Y., Hasegawa, T., 2013. Effects of elevated $\left[\mathrm{CO}_{2}\right]$ on stem and root lodging among rice Cultivars. Chinese Science Bulletten 58, 1787-1794.

Zhu, L.H., Zhong, D.B., Xu, J.L., Yu, S.B., Li, Z.K., 2008. Differential expression of lodging resistance related QTLs in rice (Oryza sativa L.). Plant Science 175, 898905. 